\title{
Effect of submucosal injection of normal saline and glycerol fructose on endoscopic polypectomy in patients with colorectal polyps
}

\author{
HAOWEN WANG and SHUANGSHUANG WANG \\ Department of Gastroenterology, Qingdao Chengyang People's Hospital, Qingdao, Shandong 266109, P.R. China
}

Received November 8, 2018; Accepted February 25, 2019

DOI: $10.3892 / 01.2019 .10120$

\begin{abstract}
Effect of submucosal injection of normal saline and glycerol fructose on endoscopic polypectomy in patients with colorectal polyps was investigated. A total of 275 patients with colorectal polyps wereenrolled in this study andunderwentendoscopic gastrointestinal polypectomy in Qingdao Chengyang People's Hospital from March 2013 to December 2016. Among them, 150 patients who underwent submucosal injection of glycerol fructose were set as the experimental group, and 125 patients who underwent submucosal injection of normal saline were set as the control group. The surgery conditions, complications and recurrence rates were compared between the two groups. The time of processing polyps and the total surgery time in the experimental group were shorter than those in the control group $(\mathrm{P}<0.05)$. The number of repeated injections in the experimental group was less than that in the control group, and the difference was statistically significant $(\mathrm{P}<0.05)$. The amount of fluid and propofol injected in patients of the experimental group was significantly lower than that of the control group, and the difference was statistically significant $(\mathrm{P}<0.05)$. The en bloc resection rate $(\mathrm{EBRR})$ and complete resection rate (CRR) in the experimental group were 68.0 and $48.0 \%$, respectively. EBRR and CRR in the control group were 49.6 and $27.2 \%$, respectively. EBRR and CRR in the experimental group were significantly higher than those in the control group $(\mathrm{P}<0.05)$. After follow-up of the patients for 3 months, there was no significant difference in the recurrence rate between the two groups $(\mathrm{P}>0.05)$. The results indicated that endoscopic colorectal polypectomy with glycerol fructose as a submucosal injection can shorten the time of surgery, reduce the number of repeated injections, reduce the amount of fluid and propofol, and also improve EBRR and CRR.
\end{abstract}

Correspondence to: Dr Haowen Wang, Department of Gastroenterology, Qingdao Chengyang People's Hospital, 600 Changcheng Road, Qingdao, Shandong 266109, P.R. China

E-mail:wmw0c5@163.com

Key words: submucosal injection, normal saline, glycerol fructose, colorectal polyps, polypectomy

\section{Introduction}

Colorectal polyps is a general term used for all the neoplasms protruding from the intestine. Colorectal polyps have a high incidence rate globally, and the detection rate of colonoscopy is 10-20\%. Among the patients with colorectal polyps, there are more male patients than females because colorectal polyps are closely related to intestinal cancer $(1,2)$. In Gastroenterology, large intestine polyps are often diagnosed and their incidence rates are constantly increasing (3). When the growth and death of colorectal epithelial cells are out of balance, and a certain degree of abnormal surface mucosal hyperplasia occurs, intestinal polyps emerge (4). Gastrointestinal polyps are roughly classified into pedicle and broad-based polyps according to their shapes (5). There are documents showing that proliferation of adenoma cancer is a general pattern of colon cancer development (6). Therefore, early detection, early treatment and post-treatment follow-up of colorectal polyps are particularly important (7).

With the rapid development of endoscopic treatment technology, endoscopic mucosal resection (EMR) has become the most common polypectomy technique, which is easy to operate and less painful for the patients. It is recognized as a method that is very safe and does less harm to patients. Also it is very convenient to operate (8) and has been widely used in clinics (9). High-frequency electric cutting is not easy under endoscopy, and there is a risk of perforation and hemorrhage. If liquid is injected into the bottom of the polyp, a layer of liquid pad is created and the polyp ascends, which can reduce the incidence rates of complications (5). It has been reported that the use of submucosal injections during surgery can separate the muscularis propria and mucosa layer. As a result, the boundary between the normal mucosa and the polyp mucosa becomes more obvious, which is beneficial in order to better grasp the range of the snare during surgery and polyp residues can be prevented. Moreover, the difference in the maintenance time of different submucosal injection fluid pads directly affects the surgical operation and wound healing (10). In recent years, the use of high-frequency electrocoagulation for the submucosal injection of saline is the most widely used method. It is also very easy to operate, and is a safe and effective mucosal resection method (11). The injection of normal saline and the tissue fluid are in an isotonic state, so they have a good compatibility. However, as the osmotic pressure of normal saline and tissue 
is the same, the endoscopic liquid pad disappears too fast during the resection process, which requires multiple injections and therefore leads to substantial inconvenience during the surgery (12). Glycerol fructose is a commonly used submucosal injection in clinical practice and is a hypertonic solution. Submucosal injection can reduce the risk of perforation and hemorrhage. Submucosal injection of glycerol fructose during endoscopic surgery does not stimulate tumor cell proliferation at the area of the wound, and its mucosal elevation is higher and longer than normal saline (13).

This study explored many aspects, such as the complications and resection rates. The effect of submucosal injection of normal saline and glycerol fructose on endoscopic polypectomy in patients with large intestine was compared.

\section{Patients and methods}

General information. A total of 275 patients with colorectal polyps who underwent endoscopic polypectomy from March 2013 to December 2016 were assigned. Among them, 150 cases who were treated with submucosal injection of glycerol fructose were set as the experimental group, including 98 cases of male patients and 52 cases of female patients, with an average age of $58.2 \pm 6.12$ years and average polyp diameter $0.93 \pm 0.23 \mathrm{~cm}$. There were 44 multiple cases, 106 single cases, 78 cases of hypertrophic polyp, 59 cases of benign polyp and 13 cases of adenomatous polyp in this group. A total of 125 cases who were treated with submucosal injection of normal saline were set as the control group, including 70 cases of male patients and 55 cases of female patients, with an average age of $58.8 \pm 5.98$ years and average polyp diameter $0.98 \pm 0.21 \mathrm{~cm}$. There were 35 multiple cases, 90 single cases, 66 cases of hypertrophic polyp, 49 cases of benign polyp and 10 cases of adenomatous polyp in this group.

Inclusion criteria: i) patients who met the diagnostic criteria for intestinal polyps (14); ii) with complete basic clinical information; iii) with polyp diameter $<2.5 \mathrm{~cm}$; iv) for which the submucosal fluid injection showed a positive sign; and v) who underwent routine examination before surgery.

Exclusion criteria: i) patients who were not actively receiving treatment; ii) with endoscopy and contraindications for treatment; iii) pregnant women; iv) patients with severe medical conditions who could not undergo surgery; and v) patients with malignant tumors, thrombocytopenia, and coagulopathy.

The study was approved by the Ethics Committee of Qingdao Chengyang People's Hospital (Qingdao, China). The experimental procedures were described to the patients in detail, and signed informed consents were obtained from the patients or their guardians.

Main drugs and instruments. Fujinon 200 series electronic colonoscope (Fujifilm Corp., Tokyo, Japan), ERBE (ICC 80) high-frequency generator (Erbe Elektromedizin $\mathrm{GmbH}$, Tuebingen, Germany), Olympus disposable polyp snare (Olympus Corp., Tokyo, Japan), injection needle (Cook Regentec, Indianapolis, IN, USA), adrenaline (national medicine Zhunzi H11020584; Beijing Yongkang Pharmaceutical Co. Ltd., Beijing, China), methylene blue (National Pharmaceutical Standard H32024827; Jiangsu Jumpcan Pharmaceutical Co.,
Ltd., Jiangsu, China), sodium chloride solution (H20056130; Beijing Shuanghe PharmaceuticalCo.,Ltd.,Beijing, China), glycerol fructose (National Pharmaceutical Standard H20043355; Zhejiang Tianrui Pharmaceutical Co., Ltd., Zhejiang, China).

Methods of treatment. Patient information was recorded and medical history was requested before surgery. For patients with constipation, oral phenolphthalein tablets were given before surgery ( 2 pieces/time, 1 or 2 times/day), applying $25 \mathrm{ml}$ of castor oil before taking the intestinal washing solution $(3,000 \mathrm{ml})$. The method of clyster was used for patients who could not take the intestinal washing solution. Patients underwent intramuscular injection of $10 \mathrm{mg}$ diazepam (National Pharmaceutical Standard H41020631; Tianjin Pharmaceutical Co., Ltd., Tianjin, China) and $10 \mathrm{mg}$ anisodamine (National Drug Standard H0000002121; Hangzhou Minsheng Pharmaceutical Co., Ltd., Hangzhou, China). Oral mannitol was not taken when cleaning the enema. The four factors of coagulation, electrocardiogram and blood routine were performed simultaneously. For older patients, ECG monitoring was also required during surgery. After the polyps were found, the feces around the polyps were first drained, the amount of inflation was increased, and it was determined whether the polyps were suitable for high-frequency electrotherapy. The snare was inserted to the biopsy hole keeping the distance between the end of inner lens and the polyp to $\sim 2 \mathrm{~cm}$. The submucosal injection for the observation group was $38 \mathrm{ml}$ of glycerol fructose, and for the control group was $38 \mathrm{ml}$ of normal saline, adding $0.4 \mathrm{ml}$ of methylene blue $(10 \mathrm{~g} / \mathrm{l})$ and $2 \mathrm{ml}$ of epinephrine $(1 \mathrm{~g} / \mathrm{l})$ for both groups. Before the polyp was removed, the submucosal injection was performed at a penetration angle of $<40^{\circ}$ until the polyp was fully lifted for resection. Polyps $>2 \mathrm{~cm}$ usually take a one-time excision or partial resection. In order to maintain the bulging state during the resection process, the injection was repeated. If the submucosal injection did not allow the lesion to remain in a raised state, then the operation needed to be terminated and converted to a surgical operation. After the polyp was removed, the wound was observed for 1-3 min until the bleeding was stopped. After surgery, patients rested and routinely antacids or antibacterials were applied. Crude fiber foods and physical activities within 2 weeks should be avoided.

Observation indexes. The operation time, the number of repeated injections, the amount of fluid used for pad injection, the time of anesthesia and dosage, the en bloc resection rate $(\mathrm{EBRR})$ and the complete resection rate (CRR) were recorded. Then, the postoperative complications and the total length of hospitalization were observed. Patients were followed up for 3 months and their recurrence was recorded until the deadline in March 2017.

Statistical analysis. Statistical analysis of experimental data was performed using SPSS 17.0 statistical software (SPSS, Inc., Chicago, IL, USA). Data counting was expressed in $\mathrm{n}(\%)$, and Chi-square test was used to compare the differences between the experimental and control group. The measurement data were expressed as the mean \pm standard deviation and paired t-test was used to compare the differences between the experimental and control group. $\mathrm{P}<0.05$ was considered to indicate a statistically significant difference. 
Table I. Comparison of general information between experimental and control group [n (\%), mean \pm standard deviation].

\begin{tabular}{|c|c|c|c|c|}
\hline Characteristics & Experimental group $(\mathrm{n}=150)$ & Control group $(\mathrm{n}=125)$ & $\chi^{2 / t}$ & P-value \\
\hline Sex & & & 2.499 & 0.114 \\
\hline Male & $98(65.3)$ & $70(56.0)$ & & \\
\hline Female & $52(34.7)$ & $55(44.0)$ & & \\
\hline Average age (years) & $58.2 \pm 6.12$ & $58.8 \pm 5.98$ & 0.818 & 0.414 \\
\hline Average weight (kg) & $75.12 \pm 6.48$ & $74.78 \pm 6.52$ & 0.432 & 0.666 \\
\hline Average height (cm) & $165.41 \pm 3.76$ & $166.12 \pm 3.82$ & 1.548 & 0.123 \\
\hline Smoking or non-smoking & & & 0.367 & 0.545 \\
\hline Smoking & $87(58.0)$ & $77(61.6)$ & & \\
\hline Non-smoking & $63(42.0)$ & $48(38.4)$ & & \\
\hline Alcoholic or non-alcoholic & & & 0.199 & 0.655 \\
\hline Alcoholic & $128(85.3)$ & $109(87.2)$ & & \\
\hline Non-alcoholic & $22(14.7)$ & $16(12.8)$ & & \\
\hline Average polyp diameter $(\mathrm{cm})$ & $0.93 \pm 0.23$ & $0.98 \pm 0.21$ & 1.867 & 0.630 \\
\hline \multicolumn{5}{|c|}{ Pathological examination classification } \\
\hline Hypertrophic polyp & $78(52.0)$ & $66(52.8)$ & 0.017 & 0.895 \\
\hline Benign polyp & $59(39.3)$ & $49(39.2)$ & 0.001 & 0.982 \\
\hline Adenomatous polyp & $13(8.7)$ & $10(8.0)$ & 0.040 & 0.842 \\
\hline Pathological type & & & 0.059 & 0.808 \\
\hline Multiple & $44(29.3)$ & $35(28.0)$ & & \\
\hline Single & $106(70.7)$ & $90(72.0)$ & & \\
\hline \multicolumn{5}{|l|}{ Area of pathogenesis } \\
\hline Rectum & $26(17.3)$ & $20(16.0)$ & 0.087 & 0.768 \\
\hline Sigmoid colon & $60(40.0)$ & $51(40.8)$ & 0.018 & 0.893 \\
\hline Descending colon & $19(12.7)$ & $16(12.8)$ & 0.001 & 0.974 \\
\hline Ascending colon & $25(16.7)$ & $22(17.6)$ & 0.042 & 0.839 \\
\hline Transverse colon & $20(13.3)$ & $16(12.8)$ & 0.017 & 0.896 \\
\hline
\end{tabular}

Table II. Comparison of surgery conditions between experimental and control group (mean \pm standard deviation).

\begin{tabular}{lccccc}
\hline Groups & $\begin{array}{c}\text { No. of } \\
\text { cases }\end{array}$ & $\begin{array}{c}\text { Time till } \\
\text { colonscope insertion } \\
\text { reached ileocecal } \\
\text { valve (min) }\end{array}$ & $\begin{array}{c}\text { Time of } \\
\text { processing } \\
\text { polyps (min) }\end{array}$ & $\begin{array}{c}\text { Total surgery time } \\
\text { (anesthesia time) } \\
\text { (min) }\end{array}$ & $\begin{array}{c}\text { No. of } \\
\text { repeated } \\
\text { injections }\end{array}$ \\
\hline Experimental group & 150 & $6.52 \pm 1.72$ & $3.61 \pm 0.59$ & $16.24 \pm 1.71$ & $1(0.7)$ \\
Control group & 125 & $6.59 \pm 1.75$ & $7.42 \pm 0.98$ & $21.08 \pm 2.21$ & $7(5.6)$ \\
$\mathrm{t} / \chi^{2}$ & & 0.333 & 39.76 & 20.46 & 5.875 \\
P-value & 0.739 & $<0.001$ & $<0.001$ & 0.015 \\
\hline
\end{tabular}

\section{Results}

Comparison of general data between the groups. As shown in Table I, there were no significant differences in terms of sex, average age, average weight, average height, smoking or non-smoking, alcoholic or non-alcoholic, average polyp diameter, pathological examination classification, pathological type, and location of the disease between the two groups $(\mathrm{P}>0.05)$, which suggested that the two groups were comparable.
Comparison of surgery time between the groups. There was no significant difference $(\mathrm{P}>0.05)$ in the time until the surgical colonscope insertion reached the ileocecal valve between the two groups. The time of polyp treatment and the total surgery time (anesthesia time) in the experimental group were shorter than those in the control group, and the differences were statistically significant ( $\mathrm{t}=39.76$ and 20.46 , respectively; $\mathrm{P}<0.05$ ). The number of repeated injections in the experimental group was less than that in the control group, and the difference was statistically significant $(\mathrm{t}=5.875, \mathrm{P}<0.05$; Table II). 
Table III. Comparison of the amounts of fluid and propofol injected in patients of the experimental and control group (mean \pm standard deviation).

\begin{tabular}{lccc}
\hline Groups & No. of cases & Injection volume $(\mathrm{ml})$ & Propofol dosage $(\mathrm{mg})$ \\
\hline Experimental group & 150 & $3.66 \pm 0.41$ & $148.65 \pm 15.23$ \\
Control group & 125 & $5.87 \pm 0.55$ & $165.23 \pm 42.34$ \\
$\mathrm{t}$ & & 38.12 & 4.463 \\
P-value & & $<0.001$ & $<0.001$ \\
\hline
\end{tabular}

Table IV. Comparison of postoperative complications between experimental and control group [n (\%)].

\begin{tabular}{|c|c|c|c|c|c|c|c|}
\hline Groups & $\begin{array}{l}\text { No. of } \\
\text { cases }\end{array}$ & $\begin{array}{l}\text { Black } \\
\text { stool }\end{array}$ & $\begin{array}{l}\text { Stomach } \\
\text { ache }\end{array}$ & $\begin{array}{c}\text { Bloody } \\
\text { stool }\end{array}$ & Perforation & $\begin{array}{l}\text { Postoperative } \\
\text { bleeding }\end{array}$ & $\begin{array}{c}\text { Incidence } \\
\text { rate }(\%)\end{array}$ \\
\hline Experimental group & 150 & $2(1.3)$ & $5(3.3)$ & $1(0.7)$ & $0(0.0)$ & $0(0.0)$ & 5.3 \\
\hline Control group & 125 & $3(2.4)$ & $4(3.2)$ & $2(1.6)$ & $0(0.0)$ & $1(0.8)$ & 8.0 \\
\hline$\chi^{2}$ & & & & & & & 0.740 \\
\hline P-value & & & & & & & 0.390 \\
\hline
\end{tabular}

Table V. Comparison of the average length of hospitalization and recurrence rate between the experimental and control group (mean \pm standard deviation).

\begin{tabular}{lccc}
\hline Groups & No. of cases & Average length of hospitalization (days) & Recurrence rate $(\%)$ \\
\hline Experimental group & 150 & $3.63 \pm 0.49$ & 0.00 \\
Control group & 125 & $3.54 \pm 0.43$ & 1.60 \\
$\chi^{2} / \mathrm{t}$ & & 1.603 & 2.02 \\
P-value & & 0.110 & 0.155 \\
\hline
\end{tabular}

Comparison of the amount of fluid and propofol injected into patients of the two groups. The amount of fluid used for pad injection and the amount of propofol used during anesthesia were significantly lower in the experimental group than that in the control group, and the differences between the two groups were statistically significant. ( $\mathrm{t}=38.12$ and 4.463 , respectively; $\mathrm{P}<0.05$; Table III).

Comparison of resection rates between the groups. EBRR and CRR in the experimental group were 68.0 and $48.0 \%$, respectively. EBRR and CRR in the control group were 49.6 and $27.2 \%$, respectively. As shown in Fig. 1, EBRR and CRR in the experimental group were higher than those in the control group, and the differences were statistically significant $(\mathrm{P}<0.05)$.

Comparison of complications between the groups. There was no perforation in the two groups of patients during surgery. Intraoperative hemorrhage occurred in 2 patients who underwent surgery and hemostasis was successful under endoscopy. In the control group, 1 patient developed postoperative hemorrhage on the 3rd day after surgery, but the amount of blood loss was small. When colonoscopy was performed again, there was a blood clot in the area of the wound and blood loss was stopped. There was no need for endoscopic hemostasis and

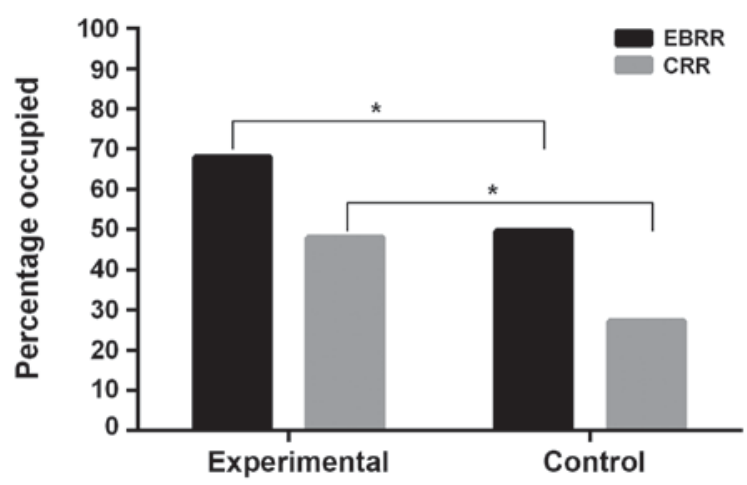

Figure 1. Comparison of the resection rates between the experimental and control group. EBRR and CRR in the experimental group were 68.0 and $48.0 \%$, respectively, and in the control group were 49.6 and $27.2 \%$, respectively. EBRR and CRR in the experimental group were higher than those in the control group, and the differences were statistically significant $\left({ }^{*} \mathrm{P}<0.05\right)$. EBRR, en bloc resection rate; $\mathrm{CRR}$, complete resection rate.

the patient was successfully discharged on the 5th day after surgery. Specific postoperative complications observed in the two groups are shown in Table IV. There was no significant difference in the incidence of postoperative complications between the two groups $(\mathrm{P}>0.05)$. 
Comparison of average length of hospitalization and recurrence rate between the groups. There was no significant difference in the average length of hospitalization between the two groups $(t=1.603, P>0.05)$. After surgery, patients were followed up for 3 months by telephone and revisiting the hospital. There was no relapse in the experimental group and only 2 patients relapsed in the control group, who were healed after treatment. There was no significant difference in the recurrence rate between the two groups $\left(\chi^{2}=2.02\right.$, $\mathrm{P}>0.05$; Table V).

\section{Discussion}

Colorectal polyps are new organisms that originate in the colon and rectal mucosa protruding into the lumen. It is a common disease of the digestive system, and the risk of developing colorectal polyps increases with age (15). Pathologically, they can be divided into adenomatous and non-adenomatous polyps. Currently, it is believed that most cases of colorectal cancer are evolved from intestinal polyps. However, adenomatous polyps account for the majority of them $(16,17)$. As age increases, the rate of polyps and the rate of malignant transformations also increase (18). There are also documents showing that the appearance of colorectal polyps may indicate the emergence of other diseases (19). Therefore, the early treatment of colorectal polyps is particularly important.

EMR is the primary treatment for colorectal polyps and can significantly reduce the risk of death from colorectal cancer (20). However, there are still risks involved in the surgery, such as infection and perforation, and especially hemorrhage which is a common complication (21). Therefore, good endoscopic skills and clinical judgment are important during surgery (22), and relevant measures to reduce the occurrence of complications should be taken. Injecting certain submucosal during EMR surgery can reduce complications and make surgery more convenient. The submucosal injections used in clinical practice are mainly normal saline and glycerin fructose. Also glycerol fructose is a hypertonic solution that has no adverse reactions to various systems and is widely used clinically (23).

In this study, there was no significant difference in the general clinical information between the experimental and control group. The surgery time in the experimental group was shorter than that in the control group. The number of repeated injections in the experimental group was less than that in the control group, and the difference was statistically significant $(\mathrm{P}<0.05)$. This indicates that glycerol fructose has a longer rising time on the mucosa than normal saline. Animal studies have shown that hypertonic solutions, other than glycerol fructose, can cause tissue damage to the mucosa (24). By comparing the amount of fluid and propofol injected in the two groups, we found that the amount used in the experimental group was less than that in the control group. Since normal saline has the same osmotic pressure as that of the tissue, the dispersion was fast. However, since glycerol fructose is a hypertonic solution that prolongs the time of the fluid pad, the number of injections were reduced. Propofol is mainly used for induction and maintenance of anesthesia and is a commonly used drug during anesthesia. It has the advantages of strong anesthesia controllability, rapid recovery after surgery and it becomes effective quickly. However, it can inhibit the human respiratory and circulatory system (25). Therefore, reducing the amount of anesthetic drugs can contribute to the safety of the patient during surgery. EBRR and CRR in the experimental group were higher than those in the control group, and the differences were statistically significant $(\mathrm{P}<0.05)$. The results showed that submucosal injection of glycerol fructose has better effect on the safety and efficacy of endoscopic surgery than normal saline. The results of the comparison between the recurrence rate of normal saline and glycerol fructose are consistent with the results of Uraoka et al (26). In this study, there was no perforation in the two groups after surgery. There was 1 case of postoperative hemorrhage in the control group, and there was no significant difference in the incidence rates of postoperative complications between the two groups. However, studies have shown that submucosal injection of glycerol fructose can reduce surgical complications (27). Also, there was no significant difference in the average length of hospitalization between the two groups. After 3 months of follow-up, there was no statistically significant difference in the recurrence rate between the two groups and incision wounds healed well in both groups. The effect of different submucosal injections on endoscopic digestive tract polypectomy were previously evaluated, and the patients were followed up for 6 months and no recurrence was found in either group (10).

In this study, we compared the general clinical information, the amount of injection and propofol used in two groups. We also compared the complications, the average length of hospitalization and recurrence rates between the two groups. A more comprehensive analysis was performed on the effects of the injection of glycerol fructose and normal saline on endoscopic resection of polyps in patients in the large intestine. There are, still relatively few comparative studies between the two groups and still many problems worthy of further study. Therefore, it is crucial to find the best treatment and submucosal injection.

In conclusion, endoscopic colorectal polypectomy with glycerol fructose as a submucosal injection can shorten the surgery time, decrease the number of repeated injections, reduce the amount of injections and dosage of propofol and increase EBRR and CRR.

\section{Acknowledgements}

Not applicable.

\section{Funding}

This study was supported by the 2013 Chengyang District People's Livelihood Science and Technology Development Project (13-14-ms).

\section{Availability of data and materials}

The datasets used and/or analyzed during the present study are available from the corresponding author on reasonable request.

\section{Authors' contributions}

HW conceived and designed the study, and drafted the manuscript. HW and SW were responsible for the analysis of the 
observation indexes. Both authors read and approved the final manuscript.

\section{Ethics approval and consent to participate}

The study was approved by the Ethics Committee of Qingdao Chengyang People's Hospital (Qingdao, China). Signed informed consents were obtained from the patients or their guardians.

\section{Patient consent for publication}

Not applicable.

\section{Competing interests}

The authors declare that they have no competing interests.

\section{References}

1. Koessler T, Bichard P, Lepilliez V, Puppa G, Ris F and Roth A: Epidemiology, treatment and follow-up of colorectal polyps. Rev Med Suisse 12: 982-988, 2016 (In French).

2. Roperch JP, Incitti R, Forbin S, Bard F, Mansour H, Mesli F, Baumgaertner I, Brunetti F and Sobhani I: Aberrant methylation of NPY, PENK, and WIF1 as a promising marker for blood-based diagnosis of colorectal cancer. BMC Cancer 13: 566, 2013.

3. Passarelli MN, Newcomb PA, Makar KW, Burnett-Hartman AN, Potter JD, Upton MP, Zhu LC, Rosenfeld ME, Schwartz SM and Rutter CM: Blood lipids and colorectal polyps: Testing an etiologic hypothesis using phenotypic measurements and Mendelian randomization. Cancer Causes Control 26: 467-473, 2015.

4. Gonçalves BM, Fontainhas V, Caetano AC, Ferreira A, Gonçalves R, Bastos P and Rolanda C: Oncological outcomes after endoscopic removal of malignant colorectal polyps. Rev Esp Enferm Dig 105: 454-461, 2013.

5. Aferzon M and Millman B: Excision of rhinophyma with high-frequency electrosurgery. Dermatol Surg 28: 735-738, 2002.

6. Wang JP, Yang ZL, Wang L, Dong WG, Huang YH, Qin JZ and Zhan WH: Multi-variate regression analysis of clinicopathological characteristics and prognosis of colorectal cancer. Zhonghua Zhong Liu Za Zhi 25: 59-61, 2003 (In Chinese).

7. Rosenberg L, Boggs D, Wise LA, Palmer JR, Roltsch MH, Makambi KH and Adams-Campbell LL: A follow-up study of physical activity and incidence of colorectal polyps in African-American women. Cancer Epidemiol Biomarkers Prev 15: 1438-1442, 2006.

8. Fabricius R, Svenningsen P, Hillings $\varnothing$ J, Svendsen LB and Sillesen M: Effect of transfusion strategy in acute non-variceal upper gastrointestinal bleeding: a nationwide study of 5861 hospital admissions in Denmark. World J Surg 40: 1129-1136, 2016.

9. Repici A, Conio M, De Angelis C, Sapino A, Malesci A, Arezzo A, Hervoso C, Pellicano R, Comunale S and Rizzetto M: Insulated-tip knife endoscopic mucosal resection of large colorectal polyps unsuitable for standard polypectomy. Am J Gastroenterol 102: 1617-1623, 2007.

10. Lang GD, Konda VJ, Siddiqui UD, Koons A and Waxman I: A single-center experience of endoscopic submucosal dissection performed in a Western setting. Dig Dis Sci 60: 531-536, 2015.

11. Ahmad NA, Kochman ML, Long WB, Furth EE and Ginsberg GG: Efficacy, safety, and clinical outcomes of endoscopic mucosal resection: a study of 101 cases. Gastrointest Endosc 55: 390-396, 2002 .
12. Miyazaki H, Kato J, Kakizaki H, Nagata T, Uetake H, Okudera H, Watanabe H, Hashimoto K and Omura K: Submucosal glycerol injection-assisted laser surgical treatment of oral lesions. Lasers Med Sci 24: 13-19, 2009.

13. Fujishiro M, Yahagi N, Kashimura K, Mizushima Y, Oka M, Enomoto S, Kakushima N, Kobayashi K, Hashimoto T, Iguchi M, et al: Comparison of various submucosal injection solutions for maintaining mucosal elevation during endoscopic mucosal resection. Endoscopy 36: 579-583, 2004.

14. Li K, Hu G, Xu M, Lu L, Wan R and Wang X: Comparison of $1.9 \mu \mathrm{m}$ Vela Laser versus high-frequency electronic knife in the treatment of digestive tract big polyps. Zhonghua Yi Xue Za Zhi 94: 3349-3351, 2014 (In Chinese).

15. Mik M, Dziki $€$, Trzciński R and Dziki A: Risk factors of 30-day mortality following surgery for colorectal cancer. Pol Przegl Chir 88: 26-31, 2016.

16. Trecca A, Gaj F and Gagliardi G: Our experience with endoscopic repair of large colonoscopic perforations and review of the literature. Tech Coloproctol 12: 315-321; discussion 322, 2008.

17. Yoon JH, Lee HL, Kim DW and Choi CR: Is obesity a risk factor for advanced colon polyps in males? Hepatogastroenterology 58: 1159-1162, 2011.

18. Corley DA, Jensen CD, Marks AR, Zhao WK, de Boer J, Levin TR, Doubeni C, Fireman BH and Quesenberry CP: Variation of adenoma prevalence by age, sex, race, and colon location in a large population: Implications for screening and quality programs. Clin Gastroenterol Hepatol 11: 172-180, 2013.

19. Karagianni V, Merikas E, Georgopoulos F, Gikas A, Athanasopoulos N, Malgarinos G, Peros G and Triantafillidis JK: Risk factors for colorectal polyps: Findings from a Greek casecontrol study. Rev Med Chir Soc Med Nat Iasi 114: 662-670, 2010

20. Zauber AG, Winawer SJ, O'Brien MJ, Lansdorp-Vogelaar I, van Ballegooijen M, Hankey BF, Shi W, Bond JH, Schapiro M, Panish JF, et al: Colonoscopic polypectomy and long-term prevention of colorectal-cancer deaths. N Engl J Med 366: 687-696, 2012

21. Dobrowolski S, Dobosz M, Babicki A, Głowacki J and Nałecz A: Blood supply of colorectal polyps correlates with risk of bleeding after colonoscopic polypectomy. Gastrointest Endosc 63: 1004-1009, 2006.

22. Herreros de Tejada A: ESD training: A challenging path to excellence. World J Gastrointest Endosc 6: 112-120, 2014.

23. Sakamaki M, Igarashi H, Nishiyama Y, Hagiwara H, Ando J, Chishiki T, Curran BC and Katayama Y: Effect of glycerol on ischemic cerebral edema assessed by magnetic resonance imaging. J Neurol Sci 209: 69-74, 2003.

24. Fujishiro M, Yahagi N, Kashimura K, Matsuura T, Nakamura M, Kakushima N, Kodashima S, Ono S, Kobayashi K, Hashimoto T, et al: Tissue damage of different submucosal injection solutions for EMR. Gastrointest Endosc 62: 933-942, 2005.

25. Suzuki K, Yoshida H, Näppi J and Dachman AH: Massive-training artificial neural network (MTANN) for reduction of false positives in computer-aided detection of polyps: Suppression of rectal tubes. Med Phys 33: 3814-3824, 2006.

26. Uraoka T, Fujii T, Saito Y, Sumiyoshi T, Emura F, Bhandari P, Matsuda T, Fu KI and Saito D: Effectiveness of glycerol as a submucosal injection for EMR. Gastrointest Endosc 61: 736-740, 2005.

27. Katsinelos P, Kountouras J, Paroutoglou G, Zavos C, Rizos C and Beltsis A: Endoscopic mucosal resection of large sessile colorectal polyps with submucosal injection of hypertonic 50 percent dextrose-epinephrine solution. Dis Colon Rectum 49: 1384-1392, 2006.

This work is licensed under a Creative Commons Attribution-NonCommercial-NoDerivatives 4.0 International (CC BY-NC-ND 4.0) License. 